\title{
Ueber Noviform.
}

Von Dr. Georg Seegall, Spezialarzt fiur Hautkrankheiten in Berlin.

Seit der Einfinhrung des Jodoforms in die antiseptische Wund. behandlung ist die chemische Industrie unablässig bemüht, wegen des vielfachen "unangenehmen Eigensehaften und Nebenwirkungen, dir diesem sonst umbertroffenen Mittel 'anhaften, Ersatzpräparate zn finden, die die hervorragende Wirksamkeit des Jodoforms ohnc dessen Nachteile besitzen. Fast unübersehbar lang ist dic Reihe derartiger Modikamente, dene'n das Beste nachgerïhmt wurdo und die doch zum großen Teil sehr schnell wieder in Vergessenheit gerieten.

Ich nenne hier nur cinige, wie: Jodoformogen, Enrophen, Airol, Jodol, Dermatol, Natrium sozojodolicum, Aristol, Glutol, Ichthoform, Jodophen, Itrol, Nosophen, Orthoform, Sanoform, Thioform, Vioform, Xeroforn etc. (Rosenthal).

Alle dieso Medikamento sollten imstande sein, das Jodoform vollig zu ersetzen; nach unseren jetzigen Erfahrungen ist dies aber bei keinem der Fall, wenngleich nicht geleugnet werden kann, dak das ene oder andere Präparat sehr gute Frfolge zeitigt. Bej den zahlreichen MiBerfolgen und Enttäuschungen, die wir so boi vielen, mit großem Enthusiasmus empfohlenen Medikamenten erleben mußten, kann es nicht wundernehnen, wenn wir etwas skeptischer gegenïber den Anpreisungen neuer Heilmittel geworden sind.

Trotzdem glaubte ich das Anerbicten eines Vertreters der Chemischen Fabrik von Heyden in Radebeul, das Noviform einer Nachprufung zu unterziehen, nicht zurïckweisen zu dürfen, weil es meines Erachtens doch nur durch immer wiederholte Versuche gelingen kann, einen vollwertigen Ersatz für das Jodoform zu finden. Ich entschloß mich um so leichter hierzu, weil einerseits die außerordentlich reich- 


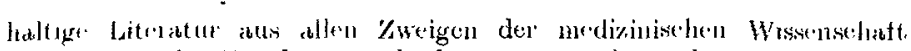

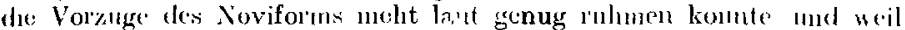

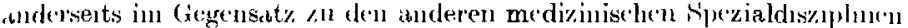

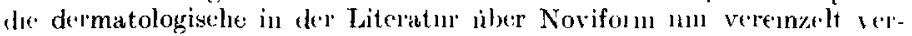

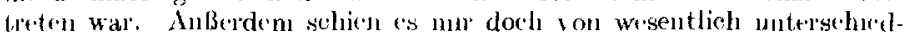
hoher Bedentumg, ob r'n Medikiment sich in Krankenlatuse bewahrt - die drei Mitteilungen von derumbologiveloer Site stammen ans dem Klankenhans resp. (ianisonspital - ofles ob e's in freier ambulanter Behandhng, bei der die Patienten sieh anter Ge'sinden minherbeweyenn

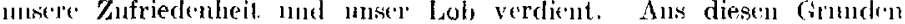
ging ich tul cine Nawhrufung de's Noviforms, die - ich will es gleich

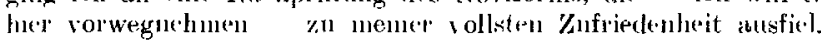

Das Noviform (Tretrabrombren\%katechnwismut), wic cs in dem

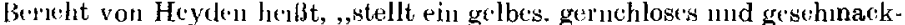
lostes Pulver voll sehr feine' Konsistenz dar. Es wirkt sekretionsvernindernd nnd anstrocknend nnd ist vollig ungiftig; daler ist sein Anwondmugsecbiet sehr groß, 's 'igne't sich zur Be-handlnng aseptischer' nind infizierter Wunden, Brtulwanden, Geschwnre ete. Zur Anwendung gelangt das Noviform in Form von Pulver, $10 \%$ iger Ca\%e, $3-20 \%$ iger Fialbc, Ntäbchen, Vaginalkngeln nud Suppositorien, Schmelzbougies nnd Pusten fur dır zahnärztliche Pr'txis."

Alle Autoren, dis bisher iber Noviform berichtet haben, (hingrgen, Gynakologen, Ophthahmologen ete, auße'n sich in gleicher Weisc zufrieden mit der Winkung des Noviforms bei Krankheiten ihres Sperziat-

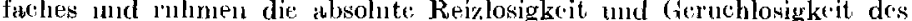
Medikamentes, das wie kanm ein andenes instande sein soll, die Bildung des Wundsekrets zu vernindern mid seblecht riechende: Winden und Crescliwiire zn desodoricren.

Nach me'ine'n eigenen Beobachtumgen wahrend einer langen Zeit an zahlreichen Fallen, deren Krankengeschichten ich nicht weiter ansfuhrlich wedergebe, kann ich abige Angaben 1111 bestatigen. loh habe: dit: ver'schiedensten Affektionen nit Noviform behandelt, wie Horpes, Phlegmonen, Pandlitien, Fun'mlel, Abscosec, aseptische und infizierte: Wunden, wic z. B. nawh Bubooperationen, Ekzene in der Umgebung von Ulzerationes der Haut etc. Wenn ich naturlich nicht in allen Fallen mit Noviform zmn Ziele kam - - es gibt mun cimmal keine Allheilmittel nud zu andere'n Mitteh meine Zuflucht nehmen mulste, so innls ich doch gestihen, daß ich no großen und ganzen von der Wirknng des Novifor'ns sehr befriedigt bin und dinnit Resnltate crzielt habe, die

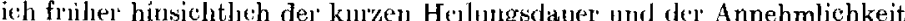
in der Anwendung nicht beobachtete. Ich crinnere mich auch nicht, jemals cine Idiosynkiasia gege'n Noviforno oder eine dureh Noviform hervorgernfenc Irritution gesehen $\%$ haben.

Hiernach mochte ich das Noviform als ein gutes Mittcl zur Wundbehandlung empfehlen, das wohl von allen Patienten infolge seiner Reiz- nnd Gerluchlosigkeit anstandsles vertragen wird und in den meisten geeigneten Fallen zur Heilmug filurt. 